\title{
RESEARCH
}

Open Access

\section{Effect of episomally encoded DNA polymerases on chemically induced mutagenesis at the hisG46 target in Ames test}

Petr Grúz ${ }^{1 *}$, Masatomi Shimizu, ${ }^{1,2}$ Kei-ichi Sugiyama', Masami Yamada ${ }^{1,3}$ and Masamitsu Honma ${ }^{1}$

\begin{abstract}
Background: The standard Ames test strains owe their high sensitivity to chemical and physical mutagens to the episomal Y-family DNA polymerase RI encoded by the muCAB operon. The S. typhimurium test strains carry also another related samAB operon on a $60-\mathrm{kDa}$ cryptic plasmid. In contrast to the chromosomally encoded Y-family DNA polymerases $V$ and $I V$, these plasmid born polymerase genes have no direct counterpart in mammalian cells. By replicating damaged templates, DNA polymerases play a central role in mutagenesis and genome stability. It is therefore imperative to investigate their specificity to understand differences in mutagenesis between the prokaryotic versus eukaryotic (mammalian) systems. To this end we have isolated and separately expressed the DNA polymerase subunits encoded by the muCAB and samAB operons. After demonstrating how these enzymes control chemical and UV mutagenesis at the standard hisD3052 and hisG428 Ames test targets, we are now adding the third Ames test target hisG46 to the trilogy.

Results: Four new Ames tester strains based on the hisG46 target have been constructed expressing the activated DNA polymerase MucA' and SamA' accessory subunits combined with the MucB and SamB catalytical subunits under the control of lac promoter. These polymerase assemblies were substituted for the endogenous PoIRI, PolV and SamAB polymerases present in the standard TA100 strain and tested for their abilities to promote chemically induced mutagenesis. SamA' + SamB has been able to promote mutagenesis induced by AF-2 and 1,8-DNP to higher extent than SamA' + MucB. The MucA' + MucB (PoIRI*) more efficiently promoted MMS as well as spontaneous mutagenesis than its wild type counterpart but was less efficient for other mutagens including AFB1. Strikingly azide mutagenesis was inhibited by PoIRI and also SamA'B.
\end{abstract}

Conclusion: A new system for SOS-independent overexpression of the activated DNA polymerases RI and SamA'B and their chimeras in the hisG46 Ames test background has been established and validated with several representative mutagens. Overall, the TA100 strain showed the highest sensitivity towards most tested mutagens. The observed inhibition of azide mutagenesis by PolRI* suggests that this type of Y-family DNA polymerases can perform also "corrective" error free replication on a damaged DNA.

Keywords: Ames test, DNA polymerase, samAB, Mutagenesis, Azide, pKM101

\footnotetext{
*Correspondence: gruz@nihs.go.jp

'Division of Genetics and Mutagenesis, National Institute of Health Sciences,

3-25-26 Tonomachi, Kawasaki-ku, Kawasaki-shi, Kanagawa 210-9501, Japan

Full list of author information is available at the end of the article
}

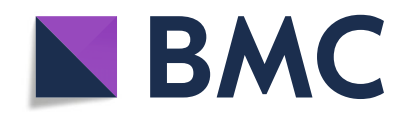

(c) The Author(s). 2020 Open Access This article is licensed under a Creative Commons Attribution 4.0 International License, which permits use, sharing, adaptation, distribution and reproduction in any medium or format, as long as you give appropriate credit to the original author(s) and the source, provide a link to the Creative Commons licence, and indicate if changes were made. The images or other third party material in this article are included in the article's Creative Commons licence, unless indicated otherwise in a credit line to the material. If material is not included in the article's Creative Commons licence and your intended use is not permitted by statutory regulation or exceeds the permitted use, you will need to obtain permission directly from the copyright holder. To view a copy of this licence, visit http://creativecommons.org/licenses/by/4.0/ The Creative Commons Public Domain Dedication waiver (http://creativecommons.org/publicdomain/zero/1.0/) applies to the data made available in this article, unless otherwise stated in a credit line to the data. 


\section{Introduction}

The Ames test has been considered a golden standard for the mutagenicity assays and is used worldwide by the government regulatory agencies to assess the safety of chemicals [1]. DNA polymerases play a key role in mutagenesis by deciding whether unrepaired damaged DNA will be tolerated and replicated often at the expense of altering the genetic code and hence introducing mutations or whether it will arrest cell division ultimately leading to death. They also shape the mutational specificity of DNA damaging genotoxicants. The Y-family DNA polymerases are evolutionary preserved group of enzymes specializing in "recognizing" and bypassing certain types of endogenous DNA lesions in an error-free manner but are highly error-prone on intact DNA or when replicating through other types of DNA lesions than they have evolved to recognize [2].

In bacteria, many Y-family DNA polymerases are encoded by plasmids spreading antibiotic resistances and have possible role in bacterial evolution helping to adapt to changing environments $[3,4]$. One of the highest error prone DNA polymerases is DNA polymerase RI encoded by the mucAB operon carried on the plasmid pKM101 [5, 6]. It is utilized in the Ames test where the pKM101 plasmid incorporated in the standard battery of strains greatly enhances sensitivity to various chemical and physical mutagens [7]. Additionally, all of the $S$. typhimurium Ames tester strains carry another 60-MDa cryptic plasmid pYQ100 which encodes the $\operatorname{sam} A B$ operon, homologous to $m u c A B$, that is inefficient in promoting mutagenesis at its natural expression levels $[4,8]$. A third Y-family DNA polymerase encoded by the chromosomal $u m u D C_{\mathrm{ST}}$ operon is also present in all of the $S$. typhimurium Ames tester strains [9, 10]. These strains possess yet fourth DNA polymerase encoded by the $\operatorname{din} B_{\mathrm{ST}}$ gene located also on the chromosome that is not contributing in greater extent to response to most mutagens similarly to $\operatorname{sam} A B$ and $u m u D C_{\mathrm{ST}}$ [11].

The activity of the Y-family polymerase core catalytical subunit such as UmuC is controlled by the accessory subunit UmuD that has to be proteolytically activated to its shorter form designated UmuD' by removal of $\mathrm{N}$ terminal tail to trigger the translesion DNA synthesis (TLS) [12]. An exception is the bacteriophage P1 that encodes already activated i.e. shorter version of UmuD called HumD [13]. This mechanism seems common to all the Y-family polymerases whose catalytic subunits are encoded by the second gene in an operon like $m u c A B$, $u m u D C$ and $\operatorname{sam} A B$ but not $\operatorname{din} B$. In this case the whole biochemically active Y-family DNA polymerase holoenzyme assembly requires also other factors like the RecA and Ssb proteins [6] and may also integrate some additional accessory proteins encoded by adjacent genes carried on conjugative plasmids such as in the case of
impCAB operon [4]. Although DNA polymerase IV encoded by the $\operatorname{din} B$ gene can replicate DNA on its own in a test tube, association with the $\beta$-subunit sliding clamp tethering it to DNA is required for achieving reasonable processivity [14-16] and this is also true for the all other DNA polymerases.

Since the Ames test is used to judge the mutagenicity of chemicals in humans, which greatly differ in the DNA polymerase repertoire, it is important to achieve the same mutation specificity in the enterobacterial cells as in the mammalian system. It is therefore important to study the properties and specificity of the prokaryotic DNA polymerases to estimate to which extent we can extrapolate the results from the Ames test to the human population. The TLS DNA polymerases play a key role in the process of converting DNA lesions to specific mutations. Although the chromosomally encoded DNA polymerases IV $(\operatorname{din} B)$ and $\mathrm{V}(u m u D C)$ are the orthologs of the human DNA polymerases $\kappa$ and $\eta$, respectively [17], the episomal DNA polymerases RI and SamAB of $S$. typhimurium are unique to bacteria and even cause malignant transformation when introduced into mouse cells [18]. It is therefore important to scrutinize the mechanisms by which the episomally encoded DNA polymerases promote mutagenesis especially in the view that the response to most mutagens in the Ames test depends on the action of the plasmid-born DNA polymerase RI which is a very powerful mutator. We have previously split the mucAB and $\operatorname{sam} A B$ operons and separately expressed the activated polymerase subunits from the IPTG-controllable lac promoter allowing to test them at various combinations, expression levels and in response to chemical or physical mutagens. To examine different mutation specificity we have already analyzed the polymerase abilities to promote base substitutions at the AT base pair (hisG428 [19];) as well as - 2 GC frameshift (hisD3052 [20];) targets of the standard Ames tester strains previously. To complete the "trilogy" we are now presenting the response of the third major Ames test target - the GC base pair substitution hotspot at the hisG46 locus - to 5 representative mutagens in the presence of various combinations of the episomal DNA polymerases.

\section{Materials and methods \\ Chemicals}

The sources of chemicals used in this study were as follows: Furylfuramide (AF-2; CAS No. 3688-53-7) and isopropyl $\beta$-D-thiogalactopyranoside (IPTG) were from Wako Pure Chemical Industries, Osaka, Japan; Methylmethane sulfonate (MMS; CAS No. 66-27-3) was purchased from Aldrich Chemical Co., Milwakukee, WI; AFB1 (CAS No. 1162-65-8) came from Sigma Chemicals, St. Louis, MO; 1,8-dinitropyrene (1,8-DNP; CAS No. 
42397-65-9) was a gift from Dr. Naoki Miyata, National Institute of Health Sciences, Tokyo, Japan and azidoglycerol (AG; CAS No. 73018-99-2) synthesized as described previously [21] was kindly provided by Dr. T. Gichner, Institute of Experimental Botany, Academy of Sciences of the Czech Republic, Prague, Czech Republic. The test mutagens were dissolved in DMSO prior to use except MMS and AG which were dissolved in water. Rat liver 9000 x g supernatant fraction (S9) from animals pretreated with phenobarbital and 5,6-benzoflavone was purchased from Kikkoman, Chiba, Japan. All other chemicals were of analytical purity and have been purchased from local supplier (Wako Pure Chemical Industries, Osaka, Japan).

\section{Bacterial strains and plasmids}

The strains used in this study are all derived from the standard Ames tester strain TA1535 carrying the hisG46 base substitution mutation target [1, 22]. The standard TA1535 and TA100 strains had been originally obtained from Bruce Ames, University of California, Berkeley. The strain YG5151 has been constructed by the preligation method routinely used for the disruption of Salmonella $u m u D C_{S T}$ and $\operatorname{sam} A B$ genes in our laboratory utilizing the kanamycin and chloramphenicol resistance cassettes as described previously $[8,20,23]$ and became a base for the construction of other strains used throughout this study. To create the PolV-deficient variant of strain TA100 named YG9056, the plasmid pKM101 has been introduced into the strain YG5151 by the bacterial conjugation technique using the E.coli strain WP2 as a donor. Other strains expressing the active forms of the episomal PolRI and SamAB DNA polymerases from an IPTG-inducible lac promoter, i.e. YG9028 and YG9029, as well as their chimerical cross-variants, i.e. YG9032 and YG9033, have been constructed by sequential transformation with the plasmids pYG8524 or pYG8529 expressing the $\operatorname{lacl}^{q}$ repressor followed by pYG8517 or pYG8518. The transformation with first passing the plasmids through the methylation helper $S$. typhimurium strain LB5000 has been carried out essentially the same as described for the related strains carrying the hisG428 (same as e.g. in TA104) and hisD3052 (same as e.g. in TA98) targets constructed in our laboratory previously [19, 20].

\section{Mutagenicity assay}

The standard Ames mutagenesis assay has been carried out as described previously with the optional 20-min preincubation procedure using S9 in the case of AFB1 [20]. The overnight cultures were grown in Bacto Nutrient Broth supplemented with $0.2 \%$ glucose and the following antibiotics as required: kanamycin at $10 \mu \mathrm{g} / \mathrm{ml}+$ chloramphenicol at $5 \mu \mathrm{g} / \mathrm{ml}$ (for all YG5151 based strains), ampicillin at $25 \mu \mathrm{g} / \mathrm{ml}$ (for the strains harboring plasmid pKM101) or ampicillin at $50 \mu \mathrm{g} / \mathrm{ml}$ (for the strains harboring plasmids pYG8524 or pYG8529) and tetracycline at $10 \mu \mathrm{g} / \mathrm{ml}$ (for the strains harboring plasmids pYG8517 or pYG8518). The S9 microsomal homogenate has been diluted $10 \mathrm{x}$ in $0.1 \mathrm{M}$ phosphate buffer with the cofactors (G-6-P $5 \mathrm{mM}$, NADPH + NADH 4 $\mathrm{mM}, \mathrm{MgCl}_{2} 8 \mathrm{mM}, \mathrm{KCl} 33 \mathrm{mM}$ ) and applied at an equivalent of $50 \mu \mathrm{l}$ per plate during the pre-incubation phase used for AFB1. IPTG has been added prior to plating to the top agar at $0.2 \mathrm{mM}$ concentration where indicated to derepress the lac promoter. The experiments were repeated at least twice and two plates were used for each dose. The mean values of $\mathrm{His}^{+}$revertants per plate are indicated in Figs. 1, 2, 3, 4, 5 and 6 and the characteristics of used strains are shown in Table 1. Selected data have been subjected to linear regression analysis to calculate the slopes of dose-response curves for each chemical which are the mutagenic potencies expressed as the specific mutagenicity values in Table 2. Only the zero and 3 initial doses within the linear range have been used for this type of analysis unless indicated otherwise as recommended by Bernstein et al. [24].

\section{Results}

Portable polymerase expression system

We have previously constructed a versatile plasmidbased system for the controllable expression of the activated Y-family DNA polymerases encoded by the episomal $m u c \mathrm{~A}+m u c \mathrm{~B}$ and $\operatorname{sam} \mathrm{A}+\operatorname{sam} \mathrm{B}$ genes in the standard S. typhimurium Ames tester strains [19]. Since the A subunits in their shorter active form designated $\mathrm{A}^{\prime}$ are expressed from an ampicillin resistant pBR322-based middle copy number replicon and the main catalytic subunits designated $\mathrm{B}$ are expressed from a compatible low copy number pSC101-based replicon, we could generate 4 types of strains expressing the natural as well as chimeric polymerase subunit combinations, i.e. MucA'+ MucB (YG9028), SamA' + SamB (YG9029), MucA' + SamB (YG9032) and SamA' + MucB (YG9033) as shown in Table 1. The strain YG9028 expresses the active form of the DNA polymerase RI, sometimes referred to as PolRI*, which has been already biochemically characterized in our and other labs and which is the enzyme responsible for the great sensitivity of the Ames tester strains like TA100, TA104, TA98 or TA97 to various chemical and physical mutagens $[6,25]$. In order to investigate the effect of these TLS DNA polymerases on mutagenesis in a "clean background" we have removed the other Y-family DNA polymerase PolV (encoded by the $u m u D C_{\mathrm{ST}}$ operon) from the chromosome as well as deleted the copy of $\operatorname{sam} A B$ from the cryptic plasmid using the kanamycin and chloramphenicol antibiotic resistance cassettes [23]. This clean background strain has been named YG5151 and used in the subsequent tests as a host for the polymerase expression system. As for 


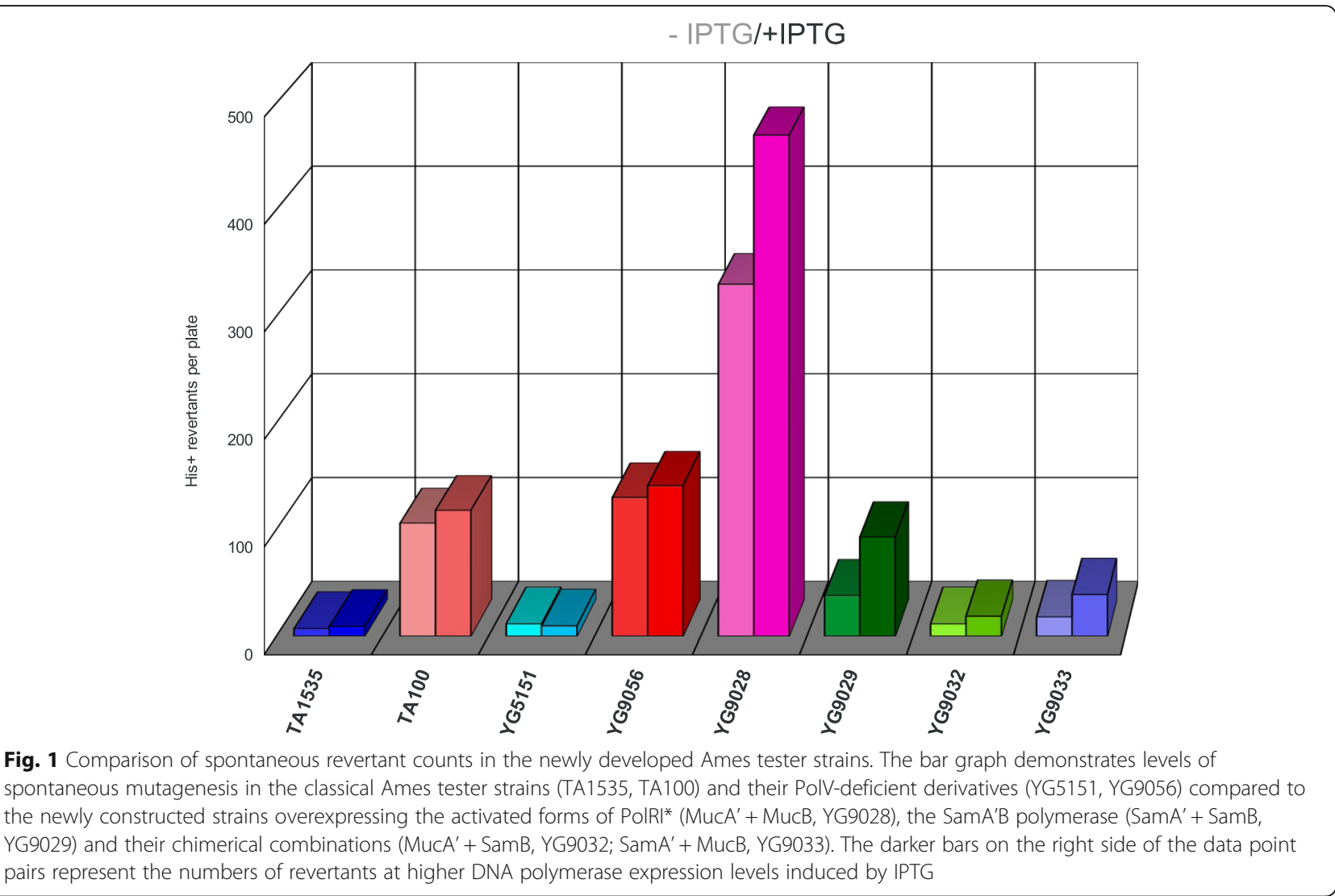

control, we have used this strain transformed with the plasmid pKM101 expressing PolRI in its native form (strain YG9056) along with the standard Ames tester strains TA100 and TA1535 (Table 1).

\section{Spontaneous mutagenesis levels in the new strains}

The strong mutagenesis promoting ability of PolRI correlates with its ability to elevate spontaneous mutation levels as can be seen in Fig. 1. The spontaneous mutant yields in strains expressing PolRI are well above the standard TA1535 background. The YG9028 strain expressing the activated PolRI has the highest spontaneous mutation level that is still marginally elevated after the lac promoter induction with IPTG. Due to its very high activity and affinity for the $\beta$-subunit sliding clamp [25], PolRI* promotes spontaneous mutagenesis even at basal leaky expression from the lac promoter and higher expression levels are actually toxic to the bacteria. We have observed strong toxicity of PolRI* expression when induced with higher IPTG concentrations added e.g. directly to the bottom agar. On the other hand the SamAB polymerase doesn't contribute to mutagenesis to any significant extent when expressed natively but raises spontaneous mutagenesis when overexpressed from the lac promoter in the activated SamA' + SamB form and upon further induction with IPTG (strain YG9029,
Fig. 1). The SamA' protein seems to counteract the PolRI* toxicity when substituted for MucA' in strain YG9033 and the ability of SamB to support spontaneous mutagenesis is lost when its SamA' partner is substituted with MucA' (strain YG9032).

\section{Chemical mutagenesis}

According to the strength of mutagenic response to the tested compounds of the used strains, three different patterns of response can be inferred from the graphs presented in Figs. 2, 3, 4, 5 and 6. First, in the case of AF-2, 1,8-DNP and AFB1 the native PolRI expressed under the SOS control from the plasmid pKM101 is better at promoting mutagenesis than its overexpressed active form PolRI* Cisplatin can be also assigned this pattern since the overexpressed activated DNA polymerases were unable to promote its mutagenesis at all (data nor shown). Second, in the case of MMS, the overexpressed activated PolRI* promotes mutagenesis better than the native pKM101-born PolRI (Fig. 3) and third, the plasmid born Y-family DNA polymerases such as PolRI actually reduce the mutagenesis as in the case of AG (Fig. 6). The SamA' + SamB proteins were able to support the mutagenesis in a dose dependent manner in the case of AF-2 and 1,8-DNP (Figs. 2 and 5) and the SamA' accessory subunit was essential for this function 

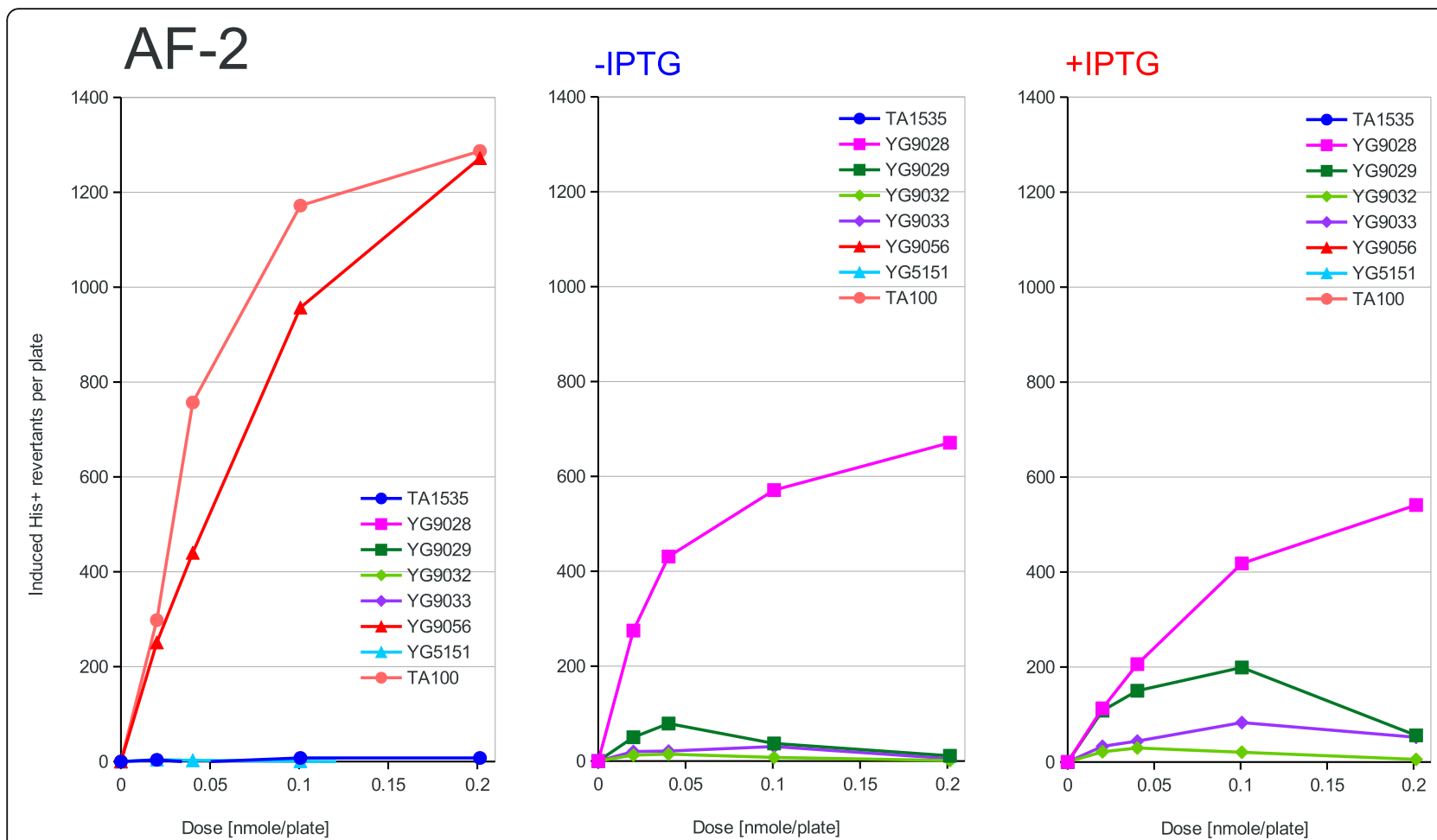

Fig. 2 Dose dependence of mutagenesis induced by AF-2. Furylfuramide (AF-2) has been applied at the doses indicated on the X-axis to the classical Ames tester strains and their PolV-deficient derivatives (left panel) or to the new Ames tester strains overexpressing the activated PolR/* and SamA'B polymerase subunits from the uninduced (middle panel) or induced (right panel) lac promoter. The induced His+ revertant counts displayed on the Y-axis were calculated by subtracting the average spontaneous revertant number for a given strain from the total number of revertants per plate values. The strains used are shown in the graph legend and described in Table 1 in detail

since its substitution with MucA' abolished the mutagenic response. The chimeric combination of SamA'+ MucB was able to promote the mutagenesis particularly by 1,8-DNP (Fig. 5) but also by AF-2, AFB1 and MMS better at higher expression levels induced by IPTG (Figs. 2, 3, 4). This contrasts with the native combination of MucA' + MucB in PolRI* which was efficient at promoting mutagenesis only at lower expression level without adding IPTG (Figs. 2, 3, 5). The unique mutagen AG defies the common sense for the mutator DNA polymerases like PolRI as these polymerases actually suppress its mutagenesis and this effect can be even enhanced by their elevated expression (Fig. 6 and Table 2). AG was also the only mutagen able to induce reversions at the hisG46 allele in the absence of any Y-family DNA polymerase.

\section{Discussion}

To help better understand the activities and specificities of the episomal Y-family DNA polymerases present in the Ames tester strains we have subcloned their subunits on separate combinable plasmids. We have also replaced their SOS-based transcription, translation and posttranslation (proteolytic) regulation with the highly efficient lac-promoter driven system controllable by IPTG [19].
Previously, we had tested the activities of these engineered polymerases at the hisG428 and hisD3052 hotspots for UV-radiation and chemically induced mutagenesis in the Ames tester strains $[19,20]$. To complete the target "trilogy", we have now introduced this PolRI* and SamA'B expression system into the hisG46 Ames test background and looked at the response to the following 5 classical mutagens: Furylfuramide (AF-2) is a member of the class of acrylamides formerly used as a food preservative in Japan and withdrawn from the market following suspicions of carcinogenicity [26]; methyl methanesulfonate (MMS) is an alkylating agent tested clinically as a cancer chemotherapeutic that acts as a strong mutagen and is reasonably anticipated to be human carcinogen [27, 28]; aflatoxin B1 (AFB1) is a potent hepatotoxic and hepatocarcinogenic mycotoxin produced by the Aspergillus flavus group of fungi which is mutagenic, teratogenic, and causes immunosuppression in animals [28, 29]; 1,8-dinitropyrene (1,8-DNP) is found in particulate emissions from combustion products of diesel exhaust and is anticipated to be a human carcinogen [28, 30]; azidoglycerol (AG) is a powerful non-carcinogenic mutagen genotoxic to bacteria, fungi and plants with a unique narrow point mutation specificity [31]. Additionally, we have also tested the antineoplastic agent cisplatin [32] known to form interstrand DNA 

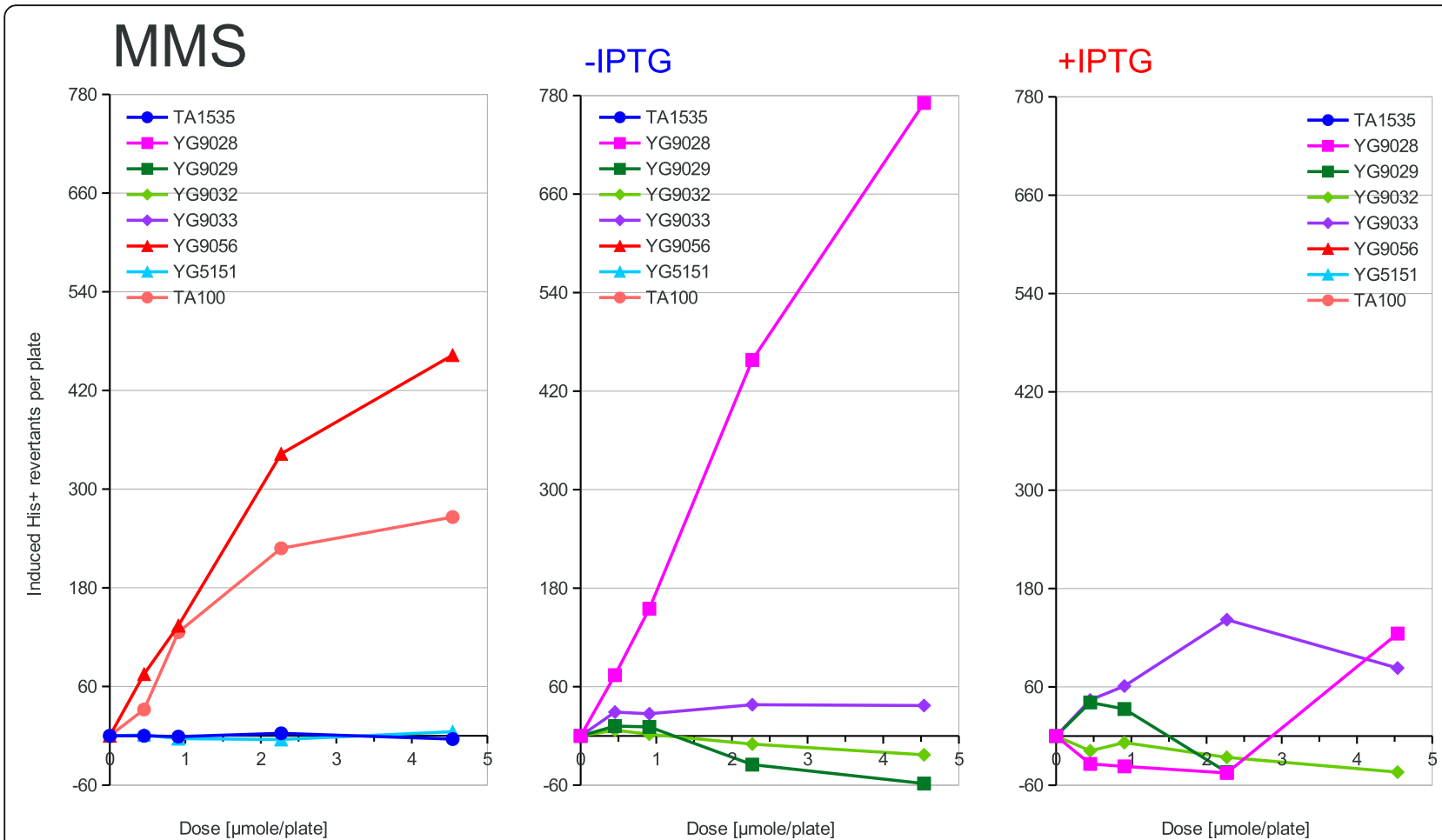

Fig. 3 Dose dependence of mutagenesis induced by MMS. Methyl methanesulfonate (MMS) has been applied at the doses indicated on the Xaxis to the classical Ames tester strains and their PolV-deficient derivatives (left panel) or to the new Ames tester strains overexpressing the activated PolRl* and SamA'B polymerase subunits from the uninduced (middle panel) or induced (right panel) lac promoter. The induced His+ revertant counts displayed on the Y-axis were calculated by subtracting the average spontaneous revertant number for a given strain from the total number of revertants per plate values. The strains used are shown in the graph legend and described in Table 1 in detail

crosslinks similarly to UV-light but we do not present the data in detail because it only showed some mutagenicity in the strains expressing PolRI from the plasmid pKM101 and not in our new strains expressing the activated PolRI". 1,8 -DNP and AF-2 are very powerful mutagens compared to the other agents in terms of how many revertants per plate are induced at the same molar amount of chemical according to Table 2.

Previously, we have already demonstrated, that the plasmid-born PolRI is essential for the lipid-peroxide induced mutagenesis at this GC hisG46 and the similar AT hisG428 base-substitution hotspots in S. typhimurium $[23,33]$. In the current work the PolRI Y-family DNA polymerase or its SamA'B counterpart also appeared essential for producing any mutations after the exposure to AF-2, MMS, AFB1, 1,8-DNP as well as cisplatin. In striking contrary, the mutagenic action of AG has been inhibited by these Y-family DNA polymerases (Fig. 6). The mutagenicity of AG is similarly to other azides independent on the SOS-system in bacteria and produces very narrow $\mathrm{G}: \mathrm{C}$ to $\mathrm{A}: \mathrm{T}$ transition mutation spectrum [21,31]. The inhibition of AG mutagenesis by PolRI could mean that the ultimate azide DNA lesion, which is still enigmatic, can be handled in an error free manner by the Y-family TLS polymerases. However, given the lack of SOS-induction after the exposure of bacteria to azides [21] this is unlikely to significantly contribute to the mutation yield under the standard conditions. It has been suggested that azido pyruvate could represent the ultimate DNA reactive mutagen in azide mutagenesis [34]. Given the very narrow mutation spectrum, it is conceivable that only the dNTP pool gets modified directly and a specific altered nucleoside is then incorporated into the nascent DNA strand by a DNA polymerase. In fact, we have observed the same mutation spectrum and dependence on DNA repair for the nucleoside analogue 8azidoadenosine (preliminary data not shown) which could therefore represent suitable ultimate azide DNA lesion candidate. What is true for other standard mutagens is seen in reverse in AG mutagenesis (Fig. 6) such as the native MucA'B and SamA'B combinations are more inhibitory that the heterogenous MucA' + SamB and SamA'+ MucB combinations. An exception is only the strain YG5151 which, after the deletion of PolV, shows decreased mutagenic response to AG suggesting possible "conventional" role of the Salmonella chromosomal $u m u D C_{\mathrm{ST}}$ genes in azide mutagenesis. This very rare inhibitory effect of a PolV-type DNA polymerase on the induced mutagenesis can be only seen in a few rare cases such as e.g. the frameshift mutations induced by Glu-P-1 [10]. 

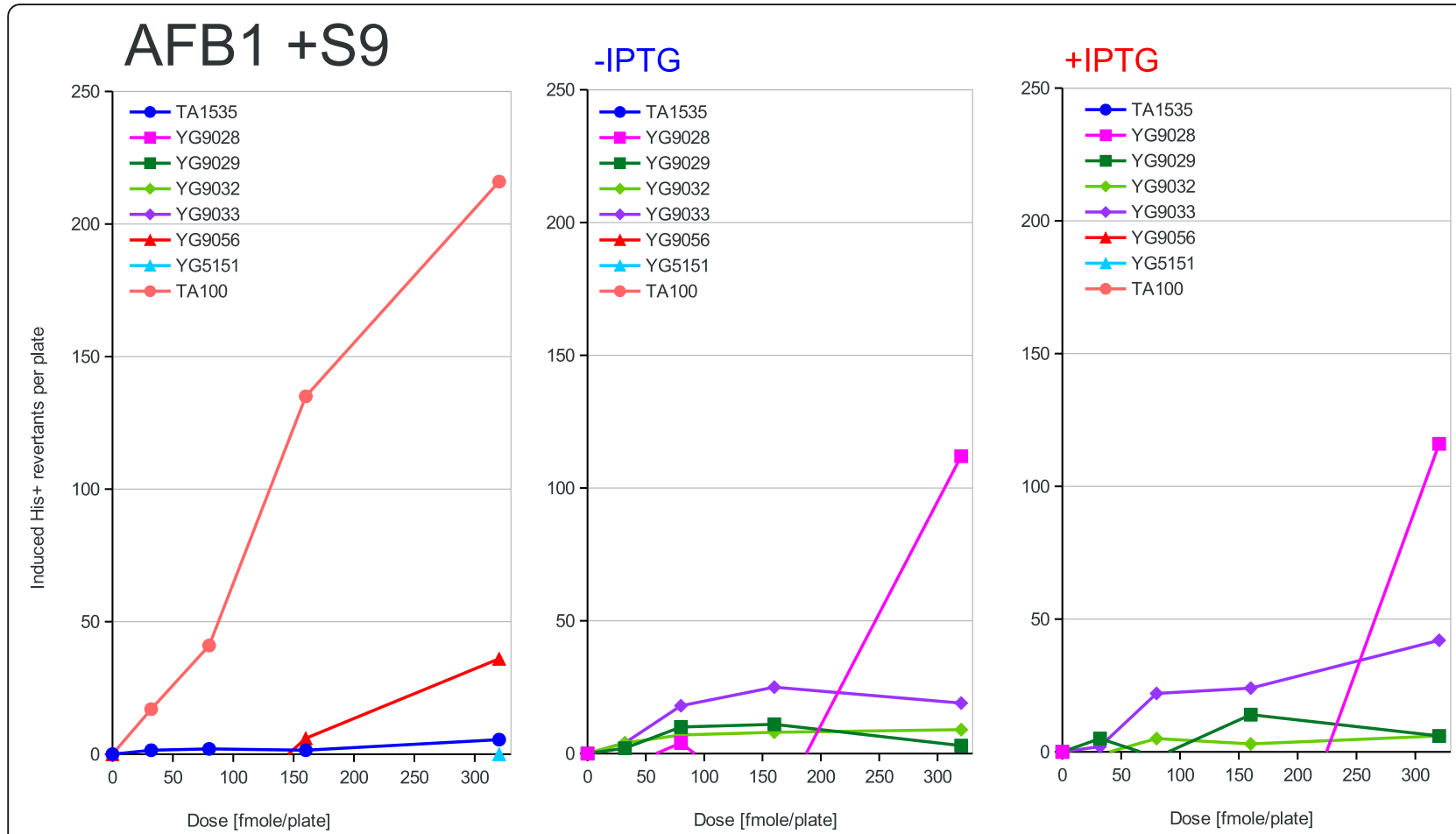

Fig. 4 Dose dependence of mutagenesis induced by AFB1. Aflatoxin B1 (AFB1) has been applied at the doses indicated on the X-axis to the classical Ames tester strains and their PolV-deficient derivatives (left panel) or to the new Ames tester strains overexpressing the activated PolRI* and SamA'B polymerase subunits from the uninduced (middle panel) or induced (right panel) lac promoter. The induced His+ revertant counts displayed on the Y-axis were calculated by subtracting the average spontaneous revertant number for a given strain from the total number of revertants per plate values. The strains used are shown in the graph legend and described in Table 1 in detail. To activate the mutagen, 20 min preincubation with rat liver 59 fraction has been carried out before plating as described in the Materials and methods section

The shorter MucA' and SamA' subunits of the polymerases seem to be essential for the base-change type mutagenesis as the expression of the sole MucB PolRI catalytical subunit (data not shown) did not promote any mutagenesis including 1,8-DNP which has been shown to be mutagenic in the presence of MucB alone in the case of nitropyrene $-2 \mathrm{GC}$ frameshift mutagenesis [20]. When highly overexpressed, upon the induction with IPTG, SamA'B has been more active in the 1,8DNP mutagenesis than PolRI* (Fig. 5) but in the case of AF-2 and AFB1 the PolRI* seems to have the upper hand (Figs. 2 and 4). The lower activity of PolRI* expressed from the lac-promoter driven system compared to the native SOS-controlled operon in the case of AF-2, AFB1 and 1,8-DNP is probably due to its stoichiometric excess related to the other processive chromosomal DNA replicases competing for binding sites on the sliding clamp [25] or could be due to yet undiscovered third subunit of PolRI encoded on the pKM101 plasmid similarly to the case of the $\operatorname{imp} C A B$ operon $[4$, 35]. The optimal level of the PolRI catalytical subunit for different DNA adducts may be linked to its occupancy at the 3 binding sites on a $\beta$-subunit sliding clamp. The sliding clamp probably acts as a tool-belt holding all polymerases needed for a complete lesion bypass together [36]. If both incorporation and extension steps during TLS across specific DNA adduct can be performed only by PolRI, the TLS would benefit from higher PolRI expression levels. However, if PolRI performs e.g. just the 3' misaligned primer extension step, lower PolRI expression level may be optimal relative to the level of the other DNA polymerase performing the first (mis) incorporation step in order not to outcompete it from the sliding clamp platform. In fact the complete lesion bypass by a single DNA polymerase subunit can be mutagenic while the bypass by combined different DNA polymerase subunits is often error free such as in the case of the thymine glycol DNA adduct [37].

We have also reported previously that the mutagenesis enhancing potential of PolRI* decreases with its increased expression while it increases in the case of SamA'B. This was true in the case of UV-light induced reversions at the AT-base substitution target hisG428 [19] as well as in the cases of AF-2, AFB1, nitropyrenes, nitrofluorene and Glu-P-1 induced - 2 GC frameshifts at the hisD3052 target of the Ames test [20]. In our present work we are seeing the same behavior at the GC-base substitution target hisG46 clearly in the case of AF-2 


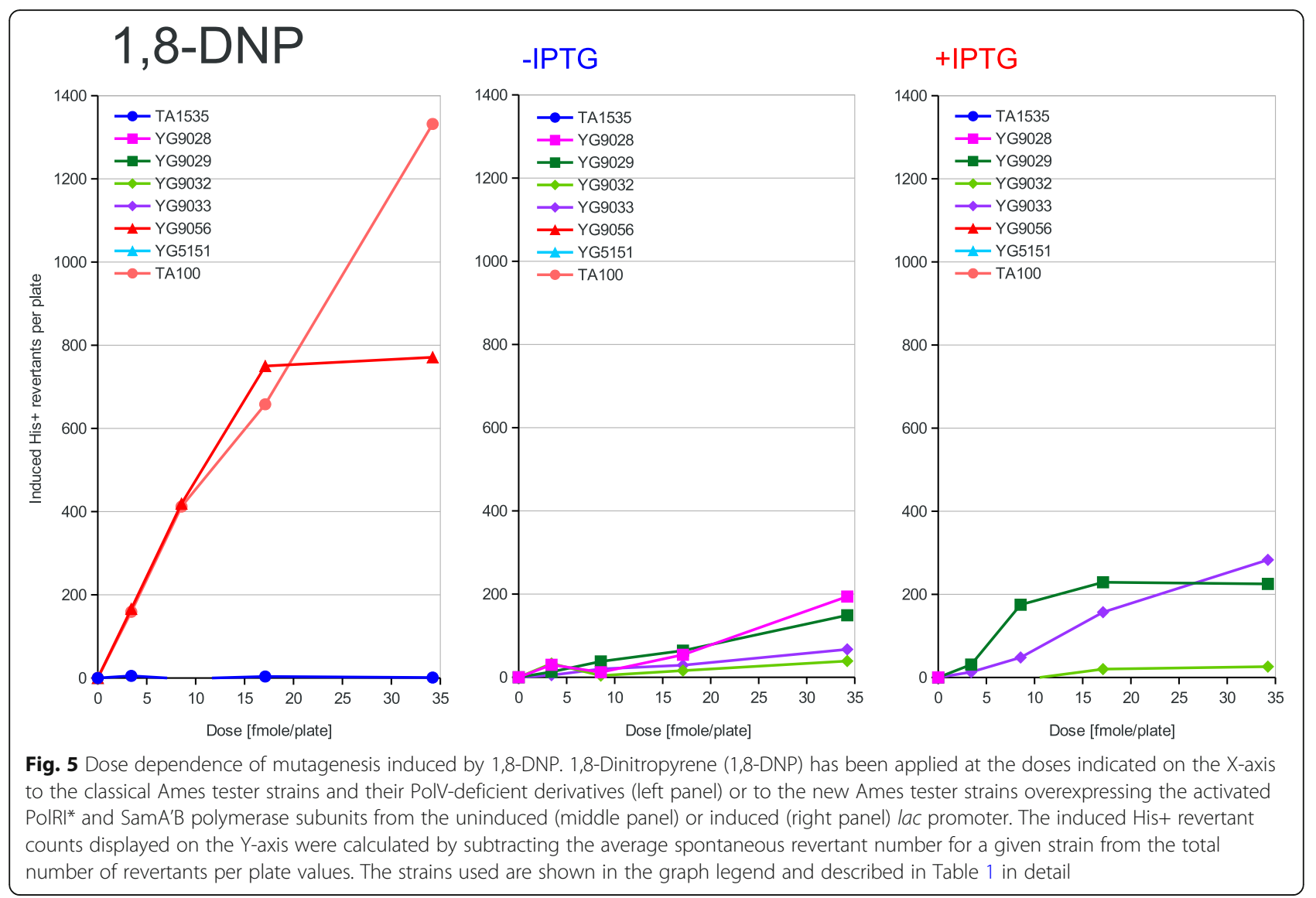

and 1,8-DNP. In contrary to the previous work, however, the MucB catalytic subunit of PolRI alone was not able to promote any mutagenesis induced by $1,8-\mathrm{DNP}$ but was able to do so in the heterogenous combination with the SamA' accessory subunit not only in the case of 1,8DNP, but also to some extent in the case of AFB1, MMS and AF-2.

The potency of PolRI, however, seems to increase with its expression level in the case of spontaneous mutagenesis (compare Fig. 1 to [19]). The lac-promoter driven PolRI* was also more efficient than the SOS plasmid born PolRI in the case of MMS alkylating mutagenesis (Fig. 3) what parallels the findings of McNally et al. that higher expression level of $m u c A B$ is more stimulating in the MMS-induced mutagenesis [38]. We have also previously shown that "more is better" for PolRI expression in the case of crotonaldehyde induced mutagenesis in the same Ames test strain background [23]. Actually the spontaneous mutants in bacteria are likely arising from endogenous alkylating damage to DNA as has been demonstrated by knocking down its repair by the $o g t_{\mathrm{ST}}$ methyltransferase in S. typhimurium [39]. On the other hand in humans not only endogenous [40] but also chemically-induced cancer-driving mutations such as that at the p53 codon \#249 after exposure to the hepatocellular carcinogen AFB1 arise from DNA lesions induced by lipid peroxidation products like crotonaldehyde [41]. In this respect our new strain offering the possibility to "fine-tune" the PolRI" overexpression level with IPTG can help to more faithfully evaluate potential human mutagens such as the longer chain lipid peroxides which are difficult to detect in the classical Ames test $[40,42]$. Overall Ames strains expressing the activated episomal Y-family TLS DNA polymerases can be useful for the detection of certain mutagens relevant to mammalian cells because they showed increased sensitivity to the propano-adduct forming lipid peroxidation products [23] but decreased sensitivity to non-carcinogenic Ames mutagens such as the azides.

The propano-adduct forming lipid peroxidation products such as crotonaldehyde and 4-hydroxy-2-nonenal have been implicated in carcinogenesis in multiple studies [40, 43-45] and are even considered to be the principal carcinogens after the exposure to other environmental mutagens such as AFB1, urban air pollution, alcohol and cigarette smoke [41, 46, 47] or during wok cooking [48]. For instance crotonaldehyde is according to IARC considered only as a Class 3 human carcinogen [49] but it is likely the principal carcinogen after the exposure to the Class 1 human carcinogen acetaldehyde $[47,50,51]$ or 

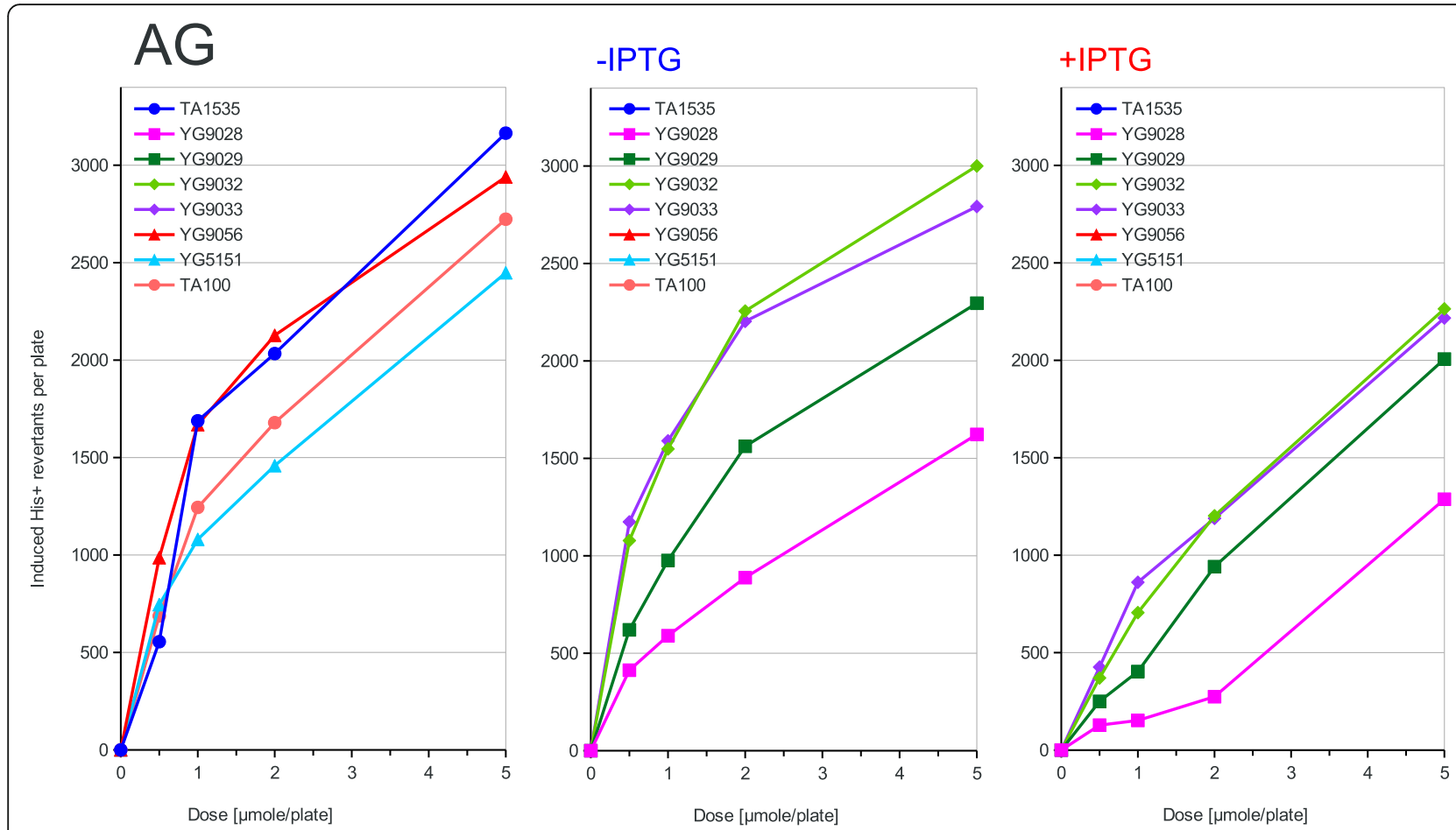

Fig. 6 Dose dependence of mutagenesis induced by AG. Azidoglycerol (AG) has been applied at the doses indicated on the X-axis to the classical Ames tester strains and their PolV-deficient derivatives (left panel) or to the new Ames tester strains overexpressing the activated PolR/* and SamA'B polymerase subunits from the uninduced (middle panel) or induced (right panel) lac promoter. The induced His+ revertant counts displayed on the $Y$-axis were calculated by subtracting the average spontaneous revertant number for a given strain from the total number of revertants per plate values. The strains used are shown in the graph legend and described in Table 1 in detail

Table 1 Characteristics of S. typhimurium strains and plasmids used in the study. Plasmids expressing Y-family DNA polymerase catalytical and accessory subunits incorporated in the Ames test strains used in present study are shown in the lower part

\begin{tabular}{|c|c|c|}
\hline Strain or plasmid & Description & Source \\
\hline \multicolumn{3}{|l|}{ Strains } \\
\hline TA1535 & hisG46, gal, $\Delta$ (chl, uvrB, bio), rfa & [1] \\
\hline TA100 & As TA1535, but harbors pKM101; Ap ${ }^{r}$ & [1] \\
\hline YG5151 & As TA1535, but $\Delta u m u D C_{S T:: K m^{r}}, \Delta s a m A B:: \mathrm{Cm}^{r}$ & This study, [23] \\
\hline YG9056 & As YG5151, but harbors pKM101; + Ap ${ }^{r}$ & This study \\
\hline YG9028 & As YG5151, but harbors pYG8524 + pYG8517; + Ap + T $c^{r}$ & This study, [23] \\
\hline YG9029 & As YG5151, but harbors pYG8529 + pYG8518; $+\mathrm{Ap}^{r}+\mathrm{TC}^{r}$ & This study \\
\hline YG9032 & As YG5151, but harbors pYG8524 + pYG8518; $+\mathrm{Ap}^{r}+T c^{r}$ & This study \\
\hline YG9033 & As YG5151, but harbors pYG8529+pYG8517; $+A p^{r}+T C^{r}$ & This study \\
\hline \multicolumn{3}{|l|}{ Plasmids } \\
\hline pKM101 & R46 derivative carrying the mucAB operon of Shigella sonnei & [7] \\
\hline pYG8524 & pBR322 derivative expressing the activated MucA' subunit of PolRI from the lac promoter & [19] \\
\hline pYG8529 & pBR322 derivative expressing the activated SamA' polymerase subunit from the lac promoter & [19] \\
\hline pYG8517 & pSC101 derivative expressing the MucB catalytic subunit of PolRI from the lac promoter & [19] \\
\hline pYG8518 & pSC101 derivative expressing the SamB polymerase subunit from the lac promoter & [19] \\
\hline
\end{tabular}


Table 2 Mutagenic potencies of tested compounds in standard TA1535 and TA100 versus new Ames tester strains overexpressing the episomal Y-family DNA polymerases. Data from tests conducted in the presence of the lac promoter inducer as described under Material and Methods are added for comparison in the columns under the IPTG label. The lac promoter drives the expression of the activated forms of DNA polymerases $\mathrm{Rl}^{*}$ and SamA'B overexpressed in the strains YG9028 and YG9029, respectively

\begin{tabular}{llllllllll}
\hline Compound & \multicolumn{6}{c}{ Specific mutagenicity [revertants/plate/nmole] } \\
\cline { 2 - 10 } & \multicolumn{2}{c}{ TA1535 } & TA100 & \multicolumn{5}{c}{ YG9028 } & \multicolumn{3}{l}{ YG9029 } \\
& & & IPTG & & IPTG & & IPTG & & IPTG \\
\hline AF-2 $\left.{ }^{*}\right)$ & - & - & 18,788 & 16,381 & 10,697 & 5113 & 1961 & 3723 \\
MMS & - & - & 0.103 & 0.099 & 0.205 & - & - & - \\
AFB1 & - & - & 846 & 692 & - & - & - & - \\
$1,8-D N P$ & - & - & 38,465 & 53,033 & 2595 & neg. & 3782 & 14,195 \\
AG & 1.047 & 1.151 & 0.817 & 0.646 & 0.42 & 0.128 & 0.753 & 0.464 \\
\hline
\end{tabular}

${ }^{*}$ only zero plus 2 first doses used for the calculations due to nonlinearity at higher doses

Class 2B human carcinogen N-nitrosopyrrolidine [52]. On the other hand the mutagen sodium azide has been shown to be non-carcinogenic in a 2-year rat study [53, 54] and its principal metabolite azidoalanine did not show any appreciable genotoxicity in mammalian cells as measured by SCEs and unscheduled DNA synthesis in Chinese hamster cells and human skin fibroblasts [55]. Likewise, AG did not enhance either chromosomal aberrations nor SCEs in human peripheral lymphocytes even at doses partially inhibiting cell division [56].

Ultimately we believe in introducing the human DNA polymerases critical for mutagenesis in mammalian cells directly into the Ames tester strains while adapting them to the prokaryotic expression and DNA replication machineries similarly as we have done in the case of the human DNA polymerase $\eta$ [57]. The higher numbers of control revertant colonies in the PolRI* expressing strains could be actually advantageous for the miniaturized Ames test formats which face basal mutant yield measurement difficulties [58]. Our system also demonstrates that the increased activity of PolRI compared to other related DNA polymerases like SamAB is not merely due to its better proteolytic activation as suggested previously [5] but due to its intrinsic activity possibly related to better targeting to the DNA via an interaction with the sliding clamp [25].

\section{Conclusions}

We have isolated the MucA', MucB, SamA' and SamB proteins expressed on separate plasmids in a controllable manner and introduced them into 3 sets of standard Ames tester strains detecting either base substitutions at the AT and GC hotspots or the -2 GC frameshifts. The overexpressed PolRI* (MucA'+ MucB) was less efficient at promoting chemically induced GC base substitutions at high expression levels but not in the case of alkylating agent and spontaneously induced mutations. Therefore, the new activated DNA polymerase RI overexpressing strain YG9028 can be useful in screening for alkylating type mutagens or antimutagens. We have also revealed the unique property of the PolRI mutator polymerase to actually suppress azide mutagenesis what is relevant to the mammalian system where azides are not considered to be mutagens. The SamA' + SamB polymerase assembly, which has not been yet characterized biochemically and is a "silent passenger" in the Ames tester strains, could also promote chemically induced mutagenesis at the hisG46 hotspot when overexpressed.

\section{Abbreviations}

AF-2, furylfuramide: 2-(2-Furyl)-3-(5-nitro-2-furyl) acrylamide; MMS: Methylmethane sulfonate; AFB1: Aflatoxin B1; 1,8-DNP: 1,8Dinitropyrene; AG, azidoglycerol: 3-Azido-1,2-propanediol; IPTG: Isopropyl $\beta$ D-thiogalactopyranoside; S. typhimurium: Salmonella typhimurium; TLS: Translesion DNA Synthesis; PoIRI: DNA polymerase Rl; PoIRI*: DNA polymerase Rl activated by MucA protein cleavage; MucA': Shorter active form of MucA protein; SamA': Shorter putative active form of SamA protein; PolV: DNA polymerase $\mathrm{V}$

\section{Acknowledgments}

The authors would like to express sincere thanks to Dr. Takehiko Nohmi, who pioneered the idea of using chimeric combinations of protein subunits later becoming known as the Y-family DNA polymerases, and to Keiko Matsui for her excellent technical support. The corresponding author would also like to acknowledge the communities involved in the development of free and open source software like LibreOffice, Zotero and Arch Linux which have been used to process the experimental data and write this manuscript without any involvement of commercial software.

\section{Authors' contributions}

PG constructed the new polymerase overexpressing plasmids and test strains, designed, oversaw and analyzed all experiments and wrote the manuscript. MY constructed the YG5151 S. typhimurium host strain. MS has validated the inhibitory effect of PolRI on azide mutagenesis. KS and MH supervised the finalization of the manuscript and agreed to be accountable for all aspects of the work. The author(s) read and approved the final manuscript.

\section{Funding}

This work was supported by Grants-in-Aid for Scientific Research (KAKENHI) Grant Number 20700600 from Japan Society for the Promotion of Science (JSPS).

\section{Availability of data and materials}

The datasets used and/or analyzed during the current study are available from the corresponding author on reasonable request.

Ethics approval and consent to participate

Not applicable.

\section{Consent for publication}

Not applicable.

\section{Competing interests}

The authors declare that they have no competing interests.

\section{Author details}

${ }^{1}$ Division of Genetics and Mutagenesis, National Institute of Health Sciences, 3-25-26 Tonomachi, Kawasaki-ku, Kawasaki-shi, Kanagawa 210-9501, Japan.

${ }^{2}$ Division of Medical Nutrition, Faculty of Healthcare, Tokyo Healthcare University, Tokyo 154-8568, Japan. ${ }^{3}$ Department of Applied Chemistry, National Defense Academy, 1-10-20 Hashirimizu, Yokosuka, Kanagawa 239-8686, Japan. 
Received: 24 November 2019 Accepted: 13 March 2020

Published online: 24 March 2020

\section{References}

1. Maron DM, Ames BN. Revised methods for the Salmonella mutagenicity test. Mutat Res Mutagen Relat Subj. 1983;113:173-215.

2. Ohmori H, Friedberg EC, Fuchs RP, Goodman MF, Hanaoka F, Hinkle D, et al. The Y-family of DNA polymerases. Mol Cell. 2001;8:7-8.

3. Permina EA, Mironov AA, Gelfand MS. Damage-repair error-prone polymerases of eubacteria: association with mobile genome elements. Gene. 2002;293:133-40.

4. Koch WH, Fernández de Henestrosa AR, Woodgate R. Identification of mucAB-like homologs on two IncT plasmids, R394 and Rts-1. Mutat Res Mol Mech Mutagen. 2000;457:1-13.

5. Hauser J, Levine AS, Ennis DG, Chumakov KM, Woodgate R. The enhanced mutagenic potential of the MuCAB proteins correlates with the highly efficient processing of the MucA protein. J Bacteriol. 1992;174:6844-51.

6. Goldsmith M, Sarov-Blat L, Livneh Z. Plasmid-encoded MucB protein is a DNA polymerase (pol RI) specialized for lesion bypass in the presence of MucA', RecA, and SSB. Proc Natl Acad Sci. 2000;97:11227-31.

7. McCann J, Spingarn NE, Kobori J, Ames BN. Detection of carcinogens as mutagens: bacterial tester strains with $\mathrm{R}$ factor plasmids. Proc Natl Acad Sci. 1975;72:979-83.

8. Nohmi T, Yamada M, Matsui K, Watanabe M, Sofuni T. Specific disruption of samAB genes in a 60-megadalton cryptic plasmid of Salmonella typhimurium. Mutat Res. 1995;329:1-9.

9. Nohmi T, Yamada M, Watanabe M, Murayama SY, Sofuni T. Roles of Salmonella typhimurium umuDC and samAB in UV mutagenesis and UV sensitivity. J Bacteriol. 1992;174:6948-55.

10. Nohmi T, Yamada M, Matsui M, Matsui K, Watanabe M, Sofuni T. Involvement of umuDCST genes in nitropyrene-induced -CG frameshift mutagenesis at the repetitive CG sequence in the hisD3052 allele of Salmonella typhimurium. Mol Gen Genet MGG. 1995:247:7-16.

11. Kokubo K, Yamada M, Kanke Y, Nohmi T. Roles of replicative and specialized DNA polymerases in frameshift mutagenesis: mutability of Salmonella typhimurium strains lacking one or all of SOS-inducible DNA polymerases to 26 chemicals. DNA Repair. 2005:4:1160-71.

12. Nohmi T, Battista JR, Dodson LA, Walker GC. RecA-mediated cleavage activates UmuD for mutagenesis: mechanistic relationship between transcriptional derepression and posttranslational activation. Proc Natl Acad Sci. 1988:85:1816-20.

13. Mclenigan MP, Kulaeva OI, Ennis DG, Levine AS, Woodgate R. The bacteriophage $\mathrm{P} 1 \mathrm{HumD}$ protein is a functional homolog of the prokaryotic UmuDJ-like proteins and facilitates SOS mutagenesis in Escherichia coli. J Bacteriol. 1999;181:9

14. Tang M, Shen X, Frank EG, O'Donnell M, Woodgate R, Goodman MF. UmuD' $2 \mathrm{C}$ is an error-prone DNA polymerase, Escherichia coli pol V. Proc Natl Acad Sci. 1999:96:8919-24.

15. Wagner J, Gruz P, Kim S-R, Yamada M, Matsui K, Fuchs RPP, et al. The dinB gene encodes a Novel E. coli DNA polymerase, DNA pol IV, involved in mutagenesis. Mol Cell. 1999:4:281-6.

16. Lenne-Samuel N, Wagner J, Etienne H, Fuchs RPP. The processivity factor $\beta$ controls DNA polymerase IV traffic during spontaneous mutagenesis and translesion synthesis in vivo. EMBO Rep. 2002:3:45-9.

17. Lee $\mathrm{CH}$, Chandani S, Loechler EL. Homology modeling of four Y-family, lesion-bypass DNA polymerases: the case that E. coli pol IV and human pol $\mathrm{K}$ are orthologs, and $\mathrm{E}$. coli pol $\mathrm{V}$ and human pol $\eta$ are orthologs. J Mol Graph Model. 2006;25:87-102.

18. Tosu M, Tanooka H. Transformation of mouse BALB 3T3 cells by enterobacterial plasmid misrepair gene mucAB. Mol Cell Biol. 1990;10:5359-64.

19. Gruz P, Matsui K, Sofuni T, Nohmi T. Construction of a new system for separate expression of mutagenesis proteins: the abilities to promote UV mutagenesis and interchangeability of MucA', MucB, SamA' and SamB proteins in Salmonella typhimurium. Mutat Res. 1996;354:157-70.

20. Gruz P, Matsui K, Sofuni T, Nohmi T. Roles of the mutagenesis proteins SamA'B and MucA'B in chemically induced frameshift mutagenesis in Salmonella typhimurium hisD3052. Mutat Res. 1998;398:33-42.

21. Grúz P, Jurícek M, Žák P, Velemínský J. Mutagenicity of 3-azido-1,2propanediol and 9-(3-azido-2-hydroxypropyl)-adenine in repair deficient strains of Escherichia coli. Mutat Res. 1993;303:1-9.
22. Mortelmans K, Zeiger E. The Ames Salmonella/microsome mutagenicity assay. Mutat Res Mol Mech Mutagen. 2000;455:29-60.

23. Grúz P, Shimizu M, Yamada M, Sugiyama K, Honma M. Opposing roles of $Y$ family DNA polymerases in lipid peroxide mutagenesis at the hisG46 target in the Ames test. Mutat Res Toxicol Environ Mutagen. 2018;829-830:43-9.

24. Bernstein L, Kaldor J, McCann J, Pike MC. An empirical approach to the statistical analysis of mutagenesis data from the Salmonella test. Mutat Res. 1982;97:267-81.

25. Grúz P, Sugiyama K, Honma M, Nohmi T. Purification and interactions of the MucA' and MucB proteins constituting the DNA polymerase Rl. Genes Environ. 2019:41:10

26. Nomura T. Carcinogenicity of the food additive furylfuramide in foetal and young mice. Nature. 1975;258:610-1.

27. National Center for Biotechnology Information. PubChem Database. Methyl methanesulfonate, $\mathrm{CID}=4156$. https://pubchem.ncbi.n/m.nih.gov/compound/ Methyl-methanesulfonate. Accessed 4 Feb 2020

28. Kim S, Chen J, Cheng T, Gindulyte A, He J, He S, et al. PubChem 2019 update: improved access to chemical data. Nucleic Acids Res. 2019;47: D1102-9.

29. National Center for Biotechnology Information. PubChem Database. CID=14403. https:/pubchem.ncbi.n/m.nih.gov/compound/14403. Accessed 4 Feb 2020.

30. National Center for Biotechnology Information. PubChem Database. 1,8Dinitropyrene, CID=39185. https://pubchem.ncbi.nlm.nih.gov/compound/1 8-Dinitropyrene. Accessed 4 Feb 2020.

31. Grúz P, Sassa A, Hosoda A, Yamagishi H, Usui Y, Shimizu M. Exclusive induction of G:C to a:T transitions by 3-azido-1,2-propanediol in yeast. Mutat Res Toxicol Environ Mutagen. 2014;760:73-6.

32. National Center for Biotechnology Information. PubChem Database. Cisplatin, $C \mid D=5702198$. https://pubchem.ncbi.nlm.nih.gov/compound/transDichlorodiamineplatinum_II. Accessed 4 Feb 2020.

33. Grúz $P$, Shimizu M, Sugiyama K, Honma M. Mutagenicity of $\omega-3$ fatty acid peroxidation products in the Ames test. Mutat Res Toxicol Environ Mutagen. 2017;819:14-9

34. Juricek M, Gruz P, Veleminsky J, Stanek J, Kefurt K, Moravcova J, et al. Mutagenic activity of 6-azido deoxyhexoses and azido alcohols in Salmonella typhimurium and its inhibition by a structure-similar carbon source in the medium. Mutat Res. 1991;251:13-20.

35. Doyle N, Strike $P$. The spectra of base substitutions induced by the impCAB, muCAB and umuDC error-prone DNA repair operons differ following exposure to methyl methanesulfonate. Mol Gen Genet MGG. 1995;247:735-41.

36. Pagès V, Fuchs RP. How DNA lesions are turned into mutations within cells? Oncogene. 2002;21:8957-66.

37. Yoon J-H, Roy Choudhury J, Park J, Prakash S, Prakash L. A role for DNA polymerase $\theta$ in promoting replication through oxidative DNA lesion, thymine glycol, in human cells. J Biol Chem. 2014;289:13177-85.

38. McNally KP, Freitag NE, Walker GC. LexA-independent expression of a mutant mucAB operon. J Bacteriol. 1990:172:6223-31.

39. Yamada M, Sedgwick B, Sofuni T, Nohmi T. Construction and characterization of mutants of Salmonella typhimurium deficient in DNA repair of O6-methylguanine. J Bacteriol. 1995;177:1511-9.

40. Grúz P. Chapter 12 - lipid peroxidation, diet, and the Genotoxicology of aging. In: Malavolta M, Mocchegiani E, editors. Molecular basis of nutrition and aging. San Diego: Academic Press; 2016. p. 155-76. https://doi.org/10. 1016/B978-0-12-801816-3.00012-1.

41. Weng M-W, Lee H-W, Choi B, Wang H-T, Hu Y, Mehta M, et al. AFB1 hepatocarcinogenesis is via lipid peroxidation that inhibits DNA repair sensitizes mutation susceptibility and induces aldehyde-DNA adducts at p53 mutational hotspot codon 249. Oncotarget. 2017;8. https://doi.org/10. 18632/oncotarget.15313

42. Marnett $\sqcup$, Hurd HK, Hollstein MC, Levin DE, Esterbauer $H$, Ames BN. Naturally occurring carbonyl compounds are mutagens in Salmonella tester strain TA104. Mutat Res. 1985:148:25-34.

43. Eder E, Budiawan. Cancer risk assessment for the environmental mutagen and carcinogen crotonaldehyde on the basis of TD50 and comparison with 1,N2-propanodeoxyguanosine adduct levels. Cancer Epidemiol Prev Biomark. 2001;10:883-8.

44. Voulgaridou G-P, Anestopoulos I, Franco R, Panayiotidis MI, Pappa A. DNA damage induced by endogenous aldehydes: current state of knowledge. Mutat Res Mol Mech Mutagen. 2011;711:13-27.

45. Hu W, Feng Z, Eveleigh J, lyer G, Pan J, Amin S, et al. The major lipid peroxidation product, trans- 4-hydroxy-2-nonenal, preferentially forms DNA 
adducts at codon 249 of human p53 gene, a unique mutational hotspot in hepatocellular carcinoma. Carcinogenesis. 2002;23:1781-9.

46. Medeiros MHG, Medeiros MHG. DNA damage by endogenous and exogenous aldehydes. J Braz Chem Soc. 2019:30:2000-9.

47. Theruvathu JA, Jaruga P, Nath RG, Dizdaroglu M, Brooks PJ. Polyamines stimulate the formation of mutagenic 1,N2-propanodeoxyguanosine adducts from acetaldehyde. Nucleic Acids Res. 2005;33:3513-20.

48. Hecht SS, Koh W-P, Wang R, Chen M, Carmella SG, Murphy SE, et al. Elevated levels of Mercapturic acids of Acrolein and Crotonaldehyde in the urine of Chinese women in Singapore who regularly cook at home. PLoS One. 2015;10. https://doi.org/10.1371/journal.pone.0120023.

49. International Agency for Research on Cancer, World Health Organization, editor. IARC monographs on the evaluation of carcinogenic risks to humans, volume 63, Dry Cleaning, Sorne Chlorinated Solvents and Other Industrial Chemicals. Lyon: IARC; 1995. https://monographs.iarc.fr/ monographs-available/.

50. Seitz HK, Stickel F. Acetaldehyde as an underestimated risk factor for cancer development: role of genetics in ethanol metabolism. Genes Nutr. 2010;5: $121-8$.

51. International Agency for Research on Cancer, Weltgesundheitsorganisation, editors. IARC monographs on the evaluation of carcinogenic risks to humans, volume $100 \mathrm{E}$, personal habits and indoor combustions: this publication represents the views and expert opinions of an IARC working group on the evaluation of carcinogenic risks to humans, which met in Lyon, 29 September - 06 October 2009. Lyon: IARC; 2012.

52. Wang MY, Chung FL, Hecht SS. Identification of crotonaldehyde as a hepatic microsomal metabolite formed by alpha-hydroxylation of the carcinogen N-nitrosopyrrolidine. Chem Res Toxicol. 1988;1:28-31.

53. National Toxicology Program. NTP Toxicology and Carcinogeneis Studies of Sodium Azide (CAS: 26628-22-8) in F344 Rats (Gavage Studies). Natl Toxicol Program Tech Rep Ser. 1991;389:1-165.

54. Hartwig A. Substance Overview for Sodium azide. In: The MAK-Collection for Occupational Health and Safety. Wiley-VCH Verlag GmbH \& Co. KGaA; 2002. https://doi.org/10.1002/3527600418.mbe2662822. https://onlinelibrary.wiley. com/page/book/10.1002/3527600418/homepage/editorscontributors.html.

55. Arenaz P, Hallberg L. Genotoxicity of azidoalanine in mammalian cells. Environ Mol Mutagen. 1989;13:263-70.

56. Jurícek M, Gichner T, Kocisová J, Yefremova Gl, Velemínský J, Staněk J, et al. Comparative mutagenicity of 3-azido-1,2-propanediol and sodium azide in various pro- and eu-karyote systems. Mutat Res. 1987;179:175-82.

57. Grúz P, Nohmi T. Expression and activity of human DNA polymerase $\eta$ in Escherichia coli. Genes Environ. 2013;35:10-20.

58. Pant K, Bruce S, Sly J, Klug Laforce M, Springer S, Cecil M, et al. Bacterial mutagenicity assays: vehicle and positive control results from the standard Ames assay, the 6-and 24-well miniaturized plate incorporation assays and the Ames $\|^{\mathrm{TM}}$ assay: screening bacterial mutagenicity assays. Environ Mol Mutagen. 2016;57:483-96.

\section{Publisher's Note}

Springer Nature remains neutral with regard to jurisdictional claims in published maps and institutional affiliations.

\section{Ready to submit your research? Choose BMC and benefit from:}

- fast, convenient online submission

- thorough peer review by experienced researchers in your field

- rapid publication on acceptance

- support for research data, including large and complex data types

- gold Open Access which fosters wider collaboration and increased citations

- maximum visibility for your research: over $100 \mathrm{M}$ website views per year

At $\mathrm{BMC}$, research is always in progress.

Learn more biomedcentral.com/submissions 